\title{
Antikörper-Screening senkt Inzidenz, aber...
}

Fragestellung: Kann ein Antikörper(AK-)Screening gegen Inselzellen bei Hochrisikopersonen helfen, dem Auftreten einer Ketoazidose vorzubeugen und den klinischen Verlauf nach der Diagnose zu beeinflussen?

Hintergrund: Die Typ-1-Diabetes-Inzidenz steigt weltweit an. Die Ketoazidose-Rate bei Diabetes im Kindes- und Jugendalter ist gleichbleibend hoch (22-29\%). Eine manifeste Ketoazidose birgt ein nicht unerhebliches Risiko für schwerwiegende Komplikationen und ist immer noch die häufigste Todesursache bei Diabetes im Kindesalter. Ein AK-Screening könnte zu einer früheren Diagnose mit milderer Manifestation führen. In Deutschland laufen mehrere Studien zum AK-Screening von Kindern und Jugendlichen. Dadurch lässt sich untersuchen, ob Patienten tatsächlich einen besseren Verlauf bei Manifestation und danach haben.

Patienten und Methodik: Bei Kindern und Jugendlichen wurde in der Münchner Familienstudie $(n=671)$ und der Babydiabstudie

Winkler C, Schober E, Ziegler A-G, Holl RW.

Markedly reduced rate of diabetic ketoacidosis at onset of type 1 diabetes in relatives screened for islet antibodies. Pediatric Diabetes 2012;12:308-13. $(\mathrm{n}=1650)$ ein AK-Screening vorgenommen. Von 604 AKpositiven Probanden entwickelten 120 einen Typ-1-Diabetes. Mithilfe eines Suchprogramms versuchte man diese in der DPV-Datenbank wiederzufinden, die für mehr als $85 \%$ al-

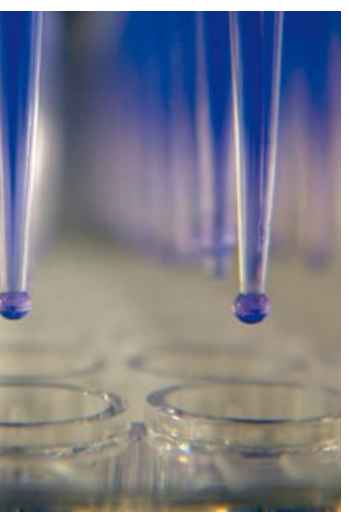

Ein Inselzell-Antikörper-Screening verringert die Ketoazidose-Rate. Nützt es aber auch längerfristig? ler Kinder und Jugendlichen mit Typ1-Diabetes in Deutschland prospektiv Verlaufsdaten sammelt. Die Studienautoren analysierten ihren Ketoazidose-Status und weiterer Parameter (Liegedauer, $\mathrm{HbA}_{1 \mathrm{c}}$ ) nach Manifestation und im Verlauf (Insulinbedarf, $\mathrm{HbA}_{1 \mathrm{c}}$, Remissionsphase).

Ergebnisse: Von 120 fanden sich 101 Typ-1-Diabetiker im DPV-Register wieder. Vom ersten positiven AK-Befund bis zur Manifestation des Diabetes vergingen im Mittel 2,8 Jahre. Im Vergleich zu nicht gescreenten Kindern hatten diejenigen aus dem Screening-Programm einen signifikant niedrigeren $\mathrm{HbA}_{1 \mathrm{c}}(8,6 \%$ vs. $11 \%)$ nach Manifestation. Eine diabetische Ketoazidose trat bei $3,3 \%$ der gescreenten Kinder und bei $29 \%$ der ungescreenten Kinder auf. Auch die stationäre Aufenthaltsdauer war signifikant kürzer (11,4 vs. 14,9 Tage). Gleiche Ergebnisse ergab der Vergleich mit Kindern, die einen erstgradigen Verwandten mit Typ-1-Diabetes hatten. Im Verlauf der nächsten fünf Beobachtungsjahre konnte zwischen den Gruppen kein Unterschied im metabolischen Verlauf $\left(\mathrm{HbA}_{1 \mathrm{c}}\right.$, Anzahl an Remissionen, Insulinbedarf) festgestellt werden.

Schlussfolgerungen: In dieser Untersuchung hatten die Kindern mit einem Screening auf Inselzell-AK eine mildere Manifestation des Typ-1-Diabetes und Komplikationen traten seltener auf. Ein substantieller Nutzen im Bezug auf Langzeitstoffwechseleinstellung konnte in dieser Studie allerdings nicht gesehen werden.

\section{- Kommentar von PD Dr. med. Thomas Kapellen}

\section{...Informationsprogramme können es kostengünstiger}

Die diabetische Ketoazidose ist eine schwerwiegende Komplikation mit dem Risiko von dauerhaften gesundheitlichen Folgen durch ein Hirnödem. Auch die psychologische Komponente eines schwerkranken Kindes auf einer Intensivstation ist nicht zu vernachlässigen und kann für Eltern und Kind ein traumatisches Erlebnis sein. Demgegenüber steht die Bürde eines Screenings, das derzeit per Definition gar nicht als solches bezeichnet werden darf, da keine präventiven Mittel zur Verhinderung eines Diabetes verfügbar sind (außer experimentelle, die in Studien angeboten werden). Auch eine Kosten-NutzenAnalyse wurde nicht unternommen. Ein generelles Screening ist bei der aktuellen Inzidenz sicher nicht rentabel. Da es auBer der Reduktion der Ketoazidose-Rate keine signifikanten Einflüsse gab, muss man überlegen, ob dieser Effekt auch durch andere Maßnahmen erreicht werden kann. Und das ist in der Tat so. Es gibt DKA-Präventionsmaßnahmen, die mit Informationsprogrammen für die Bevölkerung die Rate an Ketoazidosen fast bis auf null senken konnten.

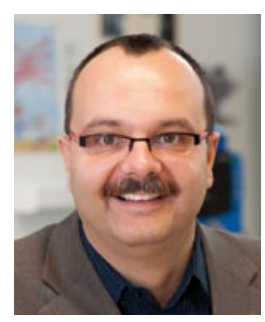

PD Dr. med. Thomas Kapellen

Oberarzt, Kinderendokrinologe und

Diabetologe

Department für Frauen- und Kindermedizin

Liebigstraße 18,

04103 Leipzig

ThomasMichael.Kapellen@

medizin.uni-leipzig.de 